\title{
Artigo
}

\section{SUJEITO, OBJETO \\ E LINGUAGEM NO \\ BRINCAR}

\section{Maria Angélica Augusto de Mello Pisetta}

atento à estrutura do brincar deixa a descoberto o processo da construção da subjetividade da criança, suas relações com o Outro da cultura de seu tempo histórico e a construção do objeto com o qual se produr um embate. Como a análise do brincar pode auxiliar na compreensão dos limites necessários ao fomento da subjetividade e da socialização na infância? É o que pretendemos discutir neste artigo.

Descritores: brincar; subjetividade; Lacan; Winnicott; psicanálise.

A maturidade do homem é ter reencontrado a seriedade com que brincava quando era criança.

Friedrich Nietzsche

\section{Brincar de fazer o mesmo: repetição, trauma e brincar}

$\int$ ones $(1989$, p. 270$)$ destaca que a visita que Freud fez a sua filha Sofie, em 1915, quando teria observado seu netinho, Ernst, a brincar com o carretel, o marcara tão profundamente que possibilitara toda sua reformulação teórica. A observação

- Psicanalista. Professora adjunta de Psicologia da Faculdade de Educação e do Programa de Pós-Graduação em Educação da Universidade Federal Fluminense, Niterói, RJ, Brasil. 
das crianças ao brincar também produziu em Winnicott inspiração para a produção de um de seus maiores conceitos, fundamentais para todos os que se dedicam a pensar o sujeito em suas relações com o Outro: o brincar como construção de uma realidade psíquica. Nossa prática voltada para a educação e clínica de crianças também se constrói continuamente na observação do brincar, em suas facetas de criação e de repetição. É na construção dessa prática que trataremos das relações entre o brincar, o Outro e o objeto. Para tanto, destacaremos no primeiro momento as relações entre o brincar e a construção da realidade psíquica e suas relações com a repetição, já anunciadas e tematizadas por Freud em 1912.

$\mathrm{Na}$ análise da brincadeira das crianças o que se destaca, para Freud (1920/2010), ao menos no primeiro momento, é o fator econômico, referido à carga pulsional, à quantidade de prazer produzido no brincar. Essa abordagem também é ressaltada por Winnicott (1971/1975), que destaca a busca do prazer como uma das características do brincar - podendo-se concluir que brincar produz prazer e satisfação. É necessário pontuar, a bem da clareza, que Winnicott publica esse trabalho especificamente sobre o conceito do brincar sessenta anos depois que Freud teorizou sobre a repetição, utilizando vários exemplos emblemáticos, como o brincar de uma criança. O pediatra psicanalista tinha, a sua percepção aguçada, uma ampla gama de experiências através das quais pôde recolher para nós as evidências da função do brincar na construção da subjetividade.

A repetição no ato de brincar é sublinhada por Freud como um jogo, que, em sua experiência direta com o brincar de seu neto, consistia em "desaparecimento e reaparição" dos objetos, seguidas das palavras Fort e $D a$, em alemão. Ação e prazer, além de compulsão por refazer o movimento, são parte integrante de toda a atividade, num laço entre o corpo da criança, o objeto jogado e resgatado, o Outro do qual ele encarna uma história e pelo qual é olhado. São todos esses elementos articulados nessa descrição:

Então era essa a brincadeira completa, desaparecimento e reaparição, de que geralmente via-se apenas o primeiro ato, que era repetido incansavelmente como um jogo em si, embora sem dúvida, o prazer maior estivesse no segundo ato (Freud, 1920/2010, p. 172).

É interessante que Freud destaque que o jogo demonstra o ganho cultural que a criança tem por uma renúncia pulsional. A que renuncia a criança quando brinca? Aqui, quando observa seu neto com as indagações sobre os maiores dilemas humanos, a pulsão de vida e a pulsão de morte, Freud percebe que se trata de um menino cuidado exclusivamente por sua mãe, que lhe dedica sua atenção e carinho. Em sua ausência, o menino se distrai, se ocupa e satisfaz com seus objetos brinquedos, aos quais faz desaparecer e ressurgir, segundo sua vontade, sem submetimento de seu domínio. A renúncia aqui, para o autor, revela um ganho 
cultural de suportar não ser amado incondicionalmente, com o auxílio de substitutos escolhidos, com os quais brinca. Acata, assim, o afastamento da mãe, sem protesto. Nas palavras de Levin (2007, p. 55),

A criança coloca nos brinquedos todo o seu amor, localizando neles a ânsia irrefreável de ser amada, e toda a fantasia se concentra em torno dessa verdade que ela deseja conquistar. Para isso, incessantemente, ela atravessa os domínios da imaginação e passa para o outro lado, onde, de maneira engenhosa, procura achar o que, sem perceber, ela própria inventa.

A linguagem aqui se torna uma conquista, e é nesse momento que o menino em questão demonstra seu primeiro domínio da linguagem articulada (oposição de dois fonemas), demonstrando, também uma apropriação inicial do meio cultural em que está inserido. É da construção de uma borda entre o sujeito e o Outro que se trata, num movimento de alienação que produz o encantamento (e o assujeitamento) do menino à força da repetição da atividade (Zwang). Freud destaca que o segundo movimento, o de fazer retornar o carretel, era o momento de produção de maior prazer.

Winnicott (1971/1975) também teoriza sobre a importância do brincar como atividade de construção subjetiva quando o define como algo para além da masturbação, ou seja, do assujeitamento pulsional auto erótico na infância. Ele ressalta que o excesso das tendências instintuais paralisa o brincar, deixando a criança fragilizada ante a experiência.

No brincar haveria prazer, segundo Freud, pela reversão de algo experimentado (como o desaparecimento da mãe), mesmo que a criança não tivesse saber sobre isso. É de 1914, do texto "Recordar, repetir e elaborar", a pontuação do autor de que, para ocorrer a repetição, não é necessário saber consciente. O brincar constrói uma fronteira onde a experiência pode ser particularizada, nomeada e precariamente dominada (Winnicott, 1971/1975)

A esse respeito, Freud destaca que o primeiro movimento, interpretado por ele como que encenando a partida da mãe, era tão importante quanto o segundo, e até mesmo mais repetido que o segundo, ressaltando que tanto o desprazer quanto o prazer devem ser levados em consideração como forças do jogo. Desejo e gozo, tomando Lacan em nossa articulação, já que Freud produz uma leitura das representações a que o carretel remete, enquanto a repetição reiterada de um desprazer nos convida a pensar a esfera do gozo. Da passividade de ser deixado (e ver partir) à atividade de trazer de volta, pelo rito da repetição, uma dança entre o desagradável e o agradável se constrói, e com ela, um sujeito.

Outro ponto que não escapa a Freud é o da vingança exercida pela criança contra seu objeto de amor, a mãe, por sua partida. Essa vingança se 
daria através da escolha por um substituto num objeto, que toma vida por sua fantasia. No mesmo caso, Freud (1914/2010, p. 174) observou um ano mais tarde, que o menino repetia o mesmo jogo, com a inclusão das palavras “Vá para a guerra!" - onde, nessa época, o pai do menino estava. Aqui o jogo erótico de domínio parece trabalhar a alienação primordial do sujeito através do brincar, como fica tão demarcado em brincadeiras que se sucedem a experiências traumáticas que as crianças passam.

Freud conclui sua análise do brincar e suas relações com o prazer e o desprazer, na borda do trauma, com o questionamento sobre o prazer evidente na repetição, tanto pelo domínio do sujeito que brinca, quanto pela vingança, no domínio do objeto. Um pouco mais adiante neste mesmo texto, Freud (1920/2010) destaca a função adicional de domínio ativo do trauma que a repetição convoca, marcando na brincadeira a função do desejo que irrompe exatamente ali onde um trauma ocorreu. Trauma e desejo se articulam, indicando inicialmente caminhos de trabalho psíquico e, adicionalmente, caminhos de tratamento psicanalítico. Essas relações que Freud estabelece entre trauma, repetição e brincar podem ser também lidas nas considerações de Winnicott, quando o autor ressalta que ao brincar a criança produz certo domínio sobre sua experiência, ainda que precário, além de alcançar outras conquistas, como o prazer e o controle do corpo. A construção da 
realidade psíquica de que nos fala Winnicott $(1971 / 1975)$ pode ser pensada como esse tratamento do trauma, trabalho sempre por fazer no brincar, através da repetição, que delimita um sujeito no encontro de seu objeto. Sua formulação de que a criança que não consegue brincar precisa ser ajudada também aponta para esse caminho de compreensão, como discutiremos a seguir.

Lembremos que Freud trabalha com a observação e teorização sobre o brincar a partir do estudo da repetição, que em si é um nó que propõe muitos desdobramentos. Num primeiro momento, o autor discute o lado desprazeroso da repetição, pelo qual um sujeito é levado a repetir, sem se dar por consciente, experiências desagradáveis. O brincar das crianças é emblemático em sua manifestação da repetição. Uma criança brinca incansavelmente da mesma coisa, até que seu interesse a leve para outra fantasia. Freud se debruça sobre isso para indagar onde está o desprazer no ato de repetir uma mesma brincadeira e conclui, nesse ponto de sua argumentação, que não há uma contradição clara ao princípio do prazer no brincar, como é evidente na fruição da criança que brinca. O que moveria a repetição, nesse caso, seria o tratamento do trauma, anterior ao brincar, aqui experimentado com a partida da mãe.

Em "De nossos antecedentes" (1966/1998, p. 71), Lacan nos diz que o trabalho de Freud em Além do princípio do prazer consiste em se desvencilhar da subordinação em que seu trabalho se mantinha em relação ao princípio do prazer, através da constatação - oscilante, como percebemos na leitura atenta deste importante texto freudiano - de que a compulsão à repetição representa de limite ao prazer e ao domínio do sujeito. O estatuto de anterioridade, ocupado até então pelo princípio do prazer, cede lugar à insistência da compulsão à repetição, prenúncio de uma esfera não representada pelo psiquismo. De fato, a compulsão à repetição vem aí como anunciadora de uma anterioridade em relação a toda simbolização, alterar o estatuto do próprio entrecruzamento simbólico do inconsciente, já tão consagrado na obra freudiana. Qual o estatuto da palavra nesse movimento?

\section{Palavra e objeto no brincar}

Foram esses jogos de ocultação que Freud numa intuição genial, produziu, a nosso ver, para que neles reconhecêssemos que o momento em que o desejo se humaniza é também aquele em que a criança nasce para a linguagem (Lacan, 1953/1998, p. 320).

O destaque que Lacan dá ao jogo do Fort-Da merece também, de nossa parte, um aprofundamento. Podemos observar que sua própria escrita, em suas 
remodelações, dá ao jogo/brincar configurações distintas, sempre discutindo as relações da linguagem no brincar com a apropriação do objeto que a criança vai conquistando. Nosso destaque se dirige, especialmente, a sua releitura em 1964 (Lacan, 1988b). Traçaremos, contudo, um pequeno panorama de suas conceituações a respeito do jogo, em alguns momentos teóricos, para destacar sua ordenação lógica.

Em O seminário, livro 1: os escritos técnicos de Freud, 1953-1954, Lacan (1987a, p. 200) acentua que o mais importante na análise do jogo é a presença do significante, marcada pela oposição dos fonemas. Assim, a criança é mestre da coisa, porque a submete pela linguagem, na construção de seu objeto. O "par simbólico" (Lacan, 1987a, p. 201) dá corpo ao objeto que vai e volta, representando-o. Kaufmann (1996, p. 474) argumenta que nesse momento teórico de Lacan não há ainda referência à cadeia significante, sendo a noção de símbolo constituída, ainda, pela influência da filosofia hegeliana, pela qual o símbolo representa a morte da coisa.

É também pela relação com a linguagem, na enunciação dos fonemas, que a criança pode mudar de posição. Assim, "a ausência é evocada na presença, e a presença, na ausência” (Kaufmann, 1996, p. 474). No jogo do Fort-Da, jogo de linguagem que guia o corpo do sujeito e o movimento do objeto, não há mais coisa, mas sujeito que constrói uma realidade e um mundo, a partir do qual a criança passa de uma posição de passividade à atuação. A apropriação da linguagem, ainda que dos fonemas, no exemplo consagrado do neto de Freud que discutimos aqui como emblema do brincar, coloca a criança em posição criativa. Sua fantasia dá andamento ao desenvolvimento de suas capacidades, dá colorido a seus sentidos, a seu olhar e encontra nos objetos à disposição no mundo as imagens que ela internaliza, já expressão de seu ser de sujeito. Desse modo, fantasia e ficção se imbricam, dando direção e vida ao brincar e aos brinquedos. Essa dinâmica produtora do brincar é assim definida por Winnicott (1971/1975, p. 87): “[Há] um interjogo na mente da criança do que é subjetivo (quase alucinação) e do que é objetivamente percebido (realidade concreta ou realidade compartilhada)".

A ênfase dada, tanto por Freud em 1920 quanto por Winnicott em 1975, de um limite presente na obtenção do prazer no brincar, não é demarcado por Lacan, nesse primeiro momento de sua análise, em que o simbólico tem ampla abrangência teórica, dando 
sustentação ao imaginário da criança e estruturando uma experiência mais tarde demarcada como real.

Em 1956-1957, a ênfase lacaniana ao jogo do Fort-Da recairá sobre a articulação que a linguagem dá ao apelo da criança. O par simbólico primitivo (representado pela alternância dos fonemas) demonstra que a criança já está imersa num mundo de linguagem, e seu interesse pela articulação desses fonemas destaca que há uma mensagem que retorna do Outro, e é tomada por ela como enigma sobre seu ser, suas escolhas, sua presença no mundo, e sobretudo, sobre o desejo desse Outro: "Desde a origem, a criança se alimenta tanto de palavras quanto de pão, e perece por palavras" (Lacan, 1995, p. 192).

Tanto a regência da linguagem no brincar quanto a construção do sujeito são pontos fundamentais de articulação aqui. Por eles, inclusive, Lacan salienta um sofrimento subjetivo constitutivo e constituinte do brincar. A palavra e seus destinos, presente na enunciação, encontram, no brinquedo e na fantasia que o alimenta, as marcas da cultura em suas múltiplas reviravoltas culturais. Sujeito e objeto enodados na cultura estão desenhados no brincar de uma criança. É também esse apelo ao Outro que se apresenta no brincar, que se construiu a partir da alternância entre uma presença e uma ausência, esta mais radical. Essa construção lacaniana é fundamental para analisarmos como as forças atuais do individualismo, consumismo e hedonismo se insinuam no simples brincar de uma criança, nas relações desse sujeito com seu objeto.

A relação entre o sujeito e o objeto, construída na tensão da separação do Outro, foi estudada por Winnicott com a inclusão de uma evidência clínica, que traz importantes articulações à teorização do objeto, constituído na fronteira do sujeito articulado ao Outro (Lacan, 1988b). Ele denomina essas evidências como "uma primeira possessão não-eu... normalmente apresentados por bebês" (Winnicott, $1971 / 1975$, p. 11) e que incluem a relação com o punho, parte do corpo, panos, um objeto duro ou mole, e que para ele podem ser pensados como "o início de um tipo afetuoso de relação de objeto". O que se apresenta como um fenômeno transicional, construindo um objeto transicional, é um de seus mais respeitados encaminhamentos, que, inclusive, abre e prepara a teorização sobre o brincar.

A precariedade do estabelecimento de um interno que possa ser teorizada como vetor a um externo faz dessa experiência uma antecâmara à relação de objeto - conforme desenvolve Lacan -, mas amplia muito a dinâmica de articulação entre o sujeito, seu objeto e o Outro do qual dá testemunho e procura separar-se em seu trabalho de subjetivação.

Introduzi os termos "objetos transicionais" e "fenômenos transicionais" para designar a área intermediária de experiência, entre o polegar e o ursinho, entre o erotismo oral e a verdadeira 
relação de objeto, entre a atividade criativa primária e a projeção do que já foi introjetado, entre o desconhecimento primário de dívida e o reconhecimento desta (Diga: "bigado") (Winnicott, 1971/1975, p. 18)

Winnicott vai demonstrar como essa possessão ilustra um tratamento psíquico primário ao trauma de ser separado de sua mãe, da qual ainda não se vê como autônomo - daí sua importância na compreensão do brincar. Pela possessão do objeto transicional, o bebê suporta, temporariamente, a separação real da qual sofre e inicia um processo de identificação que produzirá sua fantasia. Essa representação ainda carece de estruturação e o objeto transicional, por essa estrutura de borda, pode ser pensado como um objeto ainda não objetável, no sentido da separação do sujeito que o constrói com sua fantasia. Sua vinculação ao campo da experiência o situa como possessão e não como brinquedo. Nesses termos, a representação e seu amparo no simbólico, são fundamentais para pensarmos o funcionamento do brincar.

Em O seminário, livro 7: a ética da Psicanálise, 1959-1960, Lacan (1988a, p. 85) destaca que o Fort-Da, para a Psicanálise, é o marco teórico da introdução do sujeito no simbólico, pela qual se configura toda a relação do sujeito com seu objeto, representado. Marca, ainda ali, que não se trata, propriamente, de uma mediação do eu a seu objeto, mas de uma interrogação do sujeito em relação à presença ou à ausência do Outro. O brincar se insinua então como pergunta sobre o desejo do Outro e resposta subjetiva de criação, de ficção dos caminhos que o desejo da criança constrói.

Vemos o registro de uma sincronia significante entre Fort e Da, apesar de que esse jogo inicial não possa constituí-la. A autonomia do discurso (do simbólico) está enfatizada pelo autor e evidenciada no jogo, para ele, por meio da resposta que a criança procura no brincar da oposição dos fonemas. Essa oposição desenha a estrutura do significante: "Qual é o mínimo inicial concebível de uma bateria significante para que o registro do significante possa começar a se organizar?" (Lacan, 1988a, p. 85). O jogo da criança, assim, é um primeiro exercício de maestria, através da fala. A demanda da criança ao Outro que a aliena e movimenta já se apresenta enviesada pela linguagem (como de resto, toda demanda).

Como contribuição final do trabalho de Lacan a nosso esforço de pensarmos as articulações em torno do brincar da criança, trazemos seu trabalho de 1964, O seminário, livro 11: os quatro conceitos fundamentais da Psicanálise, com uma reformulação teórica mais notável, pela qual o simbólico não é mais pensado como alicerce ou estrutura primitiva. Isso mudaria o olhar para o brincar? $\mathrm{O}$ autor discute naquele momento os quatro conceitos fundamentais da Psicanálise, 
inconsciente, repetição, pulsão e transferência a partir do estabelecimento de um conceito novo: o real.

Esse conceito no pensamento lacaniano divisa um dos três nós de articulação da realidade, dos já muito discutidos até aqui, simbólico e imaginário. Embora já pudéssemos encontrar o sentido do que Lacan denomina real em outros textos precedentes do autor, agora sua teorização é mais consistente. Por essa compreensão, o real traduz uma esfera de resistência à compreensão, entendimento, imaginarização, simbolização etc. Isso pode ser exemplarmente vivido através da angústia e tem no trauma sua principal irrupção. Com esse conceito, o autor melhor articula os fenômenos de borda entre as três forças e demarca as dinâmicas entre eles.

O jogo do Fort-Da que estamos aqui comentando também é alvo de reformulação nesse novo arranjo teórico. Pela compreensão desse limite real sempre presente na expressão significante, o par Fort-Da é retomado e pensado numa nova perspectiva. Se antes Lacan destacava que a repetição incessante e prazerosa do jogo de linguagem e de objeto servia à bateria significante, e ao desempenho da maestria do sujeito em seu domínio do objeto e do trauma, agora a repetição é tomada pelo avesso. Será que repetir é chegar sempre ao mesmo lugar? Será que ao brincar, às vezes até com os mesmos movimentos, como faz uma criança que escorrega muitas vezes no mesmo brinquedo, a criança 
está buscando a mesma emoção, retornando ao mesmo ponto? Ou algo de novo se apresenta e se movimenta na compulsão à repetição?

A busca do novo ou o encontro com o novo precisam ser pensados no brincar, momento em que a criança experimenta também sua criatividade, demandada pela repetição. É o acento ao novo que movimenta o estudo da repetição para Lacan, nesse estágio de teorização do real. Assim, não é tanto um sentido que se repete, apesar de isso estar sempre presente no júbilo da criança que faz o mesmo movimento de retirar as mãos dos olhos ante o "achei" cotidiano. O psicanalista chama atenção para o além dos limites de sentido que a repetição comporta. Nesses termos, o problema que Freud apresentou do domínio sobre o desprazer, através da atividade do brincar, é pensado por Lacan agora como algo secundário. Para ele, o que se mostra mais evidente no jogo do Fort-Da é o ponto de hiância, de trauma que a ausência da mãe representa, ponto este que a criança não se cansa de vigiar em seu brincar e que deve ser trazido para a discussão de sua importância.

É como se essa ausência não deixasse de se apresentar, convocando um posicionamento do sujeito, na escolha de um objeto que dialogue com essa falta. Essa hiância - "introduzida pela ausência, desenhada e sempre aberta" (Lacan, 1988b, p. 63) - é a causa do movimento da repetição do jogo, nomeado por Lacan como o "jogo do salto". O jogo, assim, produz o desenho dessa hiância através da alternância entre uma presença e uma ausência.

Contudo, faz notar Lacan, o que falta não é o outro - a mãe - mas o próprio carretel. Não apenas o Outro falta, o próprio sujeito falta em sua possibilidade de se nomear, se representar, num trabalho psíquico sempre incompleto em relação a si mesmo. Assim, o carretel representa, agora, para Lacan, o próprio sujeito, que recebe a oposição fonemática do Fort-Da (e é suposto nesse intervalo dos significantes, num vir-a-ser). A oposição fonemática se aplica ao carretel, que, por sua vez, escancara a falta do sujeito. Sujeito e objeto faltantes constroem uma vida de brincar em que encontram um gozo.

O domínio da criança é aberto, furado, pela ausência da mãe. Lacan se refere a esse campo de domínio da criança como a borda de seu berço e a esse furo como um fosso. Esse fosso é da ordem do real, inassimilável "em torno do qual ele (o sujeito) nada mais tem a fazer senão o jogo do salto" (Lacan, 1988b). Desse modo, vemos que o jogo é uma resposta - significante - a esse buraco sem representação, desenhado pela saída da mãe. Marca então tanto a vertente significante da repetição quanto a causa real da produção desse sentido, nessa nova análise do jogo.

Lacan suplementa a análise freudiana quando considera que não é a mãe que é representada pelo carretel, mas algo do próprio sujeito: "Esse 
carretel... é alguma coisinha do sujeito que se destaca embora ainda sendo bem dele, que ele ainda segura" (Lacan, 1988b). Objeto transicional já representado, separado com o auxílio da palavra, o carretel tem vida embalado na angústia de um sujeito que se vê sem as vestes do Outro, e corre a brincar. Assegura, ainda assim, a própria fundação do sujeito pela alternância dos significantes. O domínio da criança, transformado agora em fosso, pelo real da ausência, só pode ser atravessado graças à "encantação" do jogo significante (Lacan, 1988b). O sujeito se opõe, em ato, nos diz Lacan, através desse objeto, produzindo uma fantasia que lhe dá lugar e que estrutura um Outro ao qual apelar.

Pensar o brincar a partir da repetição pode insinuar uma redução, mas toda atividade do brincar consagra a importância da repetição no trabalho de uma criança, que, para Winnicott, é um fazer, sobretudo. Toda essa atividade do Fort-Da simboliza a repetição, é sua expressão, desde que temos da repetição tanto a articulação significante ("ser um Fort de um Da e um Da de um Fort'), quanto a repetição de uma não representação original (que dá partida ao jogo).

Mais adiante, no mesmo seminário, Lacan (1988b) vai resgatar a repetição de que se trata no jogo em questão, para acentuar ainda mais seu caráter real. Destaca ele que o sujeito ali não se encontra no domínio do trauma - pelo contrário, toda repetição reiterada só demonstra a vacilação do sujeito ante a falta de representação estrutural. Assim, "nenhum sujeito pode apreender essa articulação radical" (Lacan, 1988b, p. 226). Assim, seu instrumento, o carretel, é o objeto a, com o qual sujeito tenta "remediar" essa perda traumática. Lacan marca ainda que "a função do exercício com esse objeto se refere a uma alienação" (Lacan, 1988b, p. 226). O trabalho psíquico com o corpo e o objeto que o brincar introduz são assim tratados por Lacan, e encontramos articulações possíveis com o realizado por Winnicott. Nosso esforço carece ainda de pensar como o brincar atual, muito marcado pela imagem, pode ser pensado nessa articulação do sujeito com o Outro, que na atualidade se apresenta.

\section{Considerações finais}

Procuramos discutir neste artigo como o brincar pode ser pensado pela Psicanálise, através da conversa entre as produções 
teóricas de Freud, Winnicott e Lacan das principais forças atuantes em sua expressão. Assim, num primeiro momento, enfatizamos a repetição no brincar, como pressão pulsional que incita o trabalho psíquico com o trauma, numa articulação entre o prazer e o gozo. Num segundo momento, consideramos a força da palavra e da linguagem nesse trabalho do brincar, de modo a não desconsiderar o que falha nesse processo, o real anunciado por Lacan, que convoca o trabalho psíquico de se fazer sujeito a cada novo contato com o objeto.

Para demonstrar essa articulação, alinhamos a leitura lacaniana do Fort-Da, como brincadeira que Freud utiliza para pensar a repetição, em vários momentos de seu ensino, num esforço do autor para pensar os limites do simbólico e do imaginário no embate com o real. Os laços conceituais que amarraram essa discussão - o brincar, o trauma, a palavra e o objeto - foram articulados para uma maior compreensão da importância do brincar na constituição da subjetividade de uma criança.

\section{SUBJECT, OBJECT AND LANGUAGE IN PLAYING}

\section{Abstract}

Playing is such a common activity in childhood that its theorizing slips into a certain truism. Everyone can witness, daily, the children's need to play and the sociocultural advances that they demonstrate, when they have their time to fantasize and play respected and empowered. A closer look at the structure of play reveals the process of constructing the children's subjectivity, their relations with the Other of the culture of their historical time, and the construction of the object with which a conflict occurs. How can playing analysis help understanding the limits necessary to foster subjectivity and socialization in childhood? This is what we intend to discuss in this article.

Index terms: playing; subjectivity; Lacan; Winnicott; psychoanalysis.

\section{EL SUJETO, EL OBJETO Y EL LENGUAJE EN EL JUEGO}

\section{Resumen}

El juego es una actividad tan común en la infancia que su teoría muestra cierta evidencia. Todo el mundo puede ser testigo todos los días de la necesidad que tienen los niños para jugary los avances socio-culturales que muestran, cuando se respeta y se estimula su tiempo de fantaseary jugar. Una mirada más cercana a la estructura de la obra descubre el proceso de construcción de la subjetividad del niño, sus relaciones con el Otro de la cultura de su tiempo histórico y la construcción del objeto con el que se produce un choque. ¿En qué medida el análisis del juego puede ayudar a comprender los límites necesarios para el desarrollo de la subjetividad y la socialización en la infancia? Esto es lo que nos proponemos discutir en este texto.

Palabras clave: jugar; subjetividad; Lacan; Winnicott; psicoanálisis. 


\section{REFERÊNCIAS}

Freud, S. (2010). Recordar, repetir e elaborar. In S. Freud, Sigmund Freud: obras completas (P. Souza, trad., Vol. 10, pp. 193-209). São Paulo, SP: Companhia das Letras. (Trabalho original publicado em 1914)

Freud, S. (2010) Além do princípio do prazer. In S. Freud, Sigmund Freud, obras completas (P. Souza, trad., Vol. 14, pp. 161-239). São Paulo, SP: Companhia das Letras. (Trabalho original publicado em 1920).

Jones, E. (1989). A vida e a obra de Sigmund Freud (Vol. 1). Rio de Janeiro, RJ: Imago.

Kaufmann, P. (1996). Simbólico. In P. Kaufmann (Ed.), Dicionário Enciclopédico de Psicanálise: o legado de Freud e Lacan. (V. Ribeiro, trad., pp. 474-479). Rio de Janeiro, RJ: Jorge Zahar.

Lacan, J. (1987a). O seminário, livro 1: os escritos técnicos de Freud, 1953-1954. Rio de Janeiro, RJ: Jorge Zahar.

Lacan, J. (1987b). O seminário, livro 2: o eu na teoria de Freud e na técnica da Psicanálise, 1954-1955. Rio de Janeiro, RJ: Jorge Zahar.

Lacan, J. (1988a). O seminário, livro 7: a ética da Psicanálise, 1959-1960. Rio de Janeiro, RJ: Jorge Zahar.

Lacan, J. (1988b). O seminário, livro 11: os quatro conceitos fundamentais da Psicanálise, 1964. Rio de Janeiro, RJ: Jorge Zahar.

Lacan, J. (1995). O seminário, livro 4: a relação de objeto, 1956-1957. Rio de Janeiro, RJ: Jorge Zahar.

Lacan, J. (1998). De nossos antecedentes. In J. Lacan, Escritos (V. Ribeiro, trad., pp. 69-71). Rio de Janeiro, RJ: Jorge Zahar. (Trabalho original publicado em 1966)

Lacan, J. (1998). Função e campo da fala e da linguagem em psicanálise. In J. Lacan, Escritos (V. Ribeiro, trad., pp. 238-324). Rio de Janeiro, RJ: Jorge Zahar.

Levin, E. (2007). Rumo a uma infância virtual? A imagem corporal sem corpo. Petrópolis, RJ: Vozes.

Pisetta, M. A. A. M. (2015). Linguagem e cotidiano escolar: contribuiçóes da Psicanálise. In L. Lehmann, \& 1. G. Coutinho (Org.), Psicologia e educação: interfaces (pp. 111-122) Niterói, RJ: Eduff.

Winnicott, D. W. (1975). O brincar e a realidade. São Paulo, SP: Coleção Psicologia Psicanalítica. (Trabalho original publicado em 1971)

angelicapisetta@gmail.com.br

Rua Raul Veiga, 105. 25650-110 - Petrópolis - RJ - Brasil.

Recebido em agosto/2016. Aceito em dezembro/2016. 